\title{
$B R A F$ V600E status may facilitate decision-making on active surveillance of low-risk papillary thyroid microcarcinoma
}

\author{
Kyeong J. Kim ${ }^{\mathrm{a}, \mathrm{b}}$, Sin G. Kim ${ }^{\mathrm{b}}$, Jie Tan ${ }^{\mathrm{a}}$, Xiaopei Shen ${ }^{\mathrm{a}}$, David Viola ${ }^{\mathrm{c}}$, \\ Rossella Elisei ${ }^{c}$, Efisio Puxeddu ${ }^{\mathrm{d}}$, Laura Fugazzola ${ }^{\mathrm{e}}$, Carla Colombo ${ }^{\mathrm{e}}$, \\ Barbara Jarzab ${ }^{\mathrm{f}}$, Agnieszka Czarniecka ${ }^{\mathrm{f}}$, Alfred K. Lam ${ }^{\mathrm{g}}$, \\ Caterina Mian ${ }^{\mathrm{h}}$, Federica Vianello ${ }^{\mathrm{i}}$, Linwah Yip ${ }^{\mathrm{j}}$, \\ Garcilaso Riesco-Eizaguirre ${ }^{\mathrm{k}, 1, \mathrm{~m}}$, Pilar Santisteban ${ }^{1, \mathrm{~m}}$, \\ Christine J. O'Neill ${ }^{\mathrm{n}}$, Mark S. Sywak ${ }^{\mathrm{n}}$, Roderick Clifton-Bligh ${ }^{\mathrm{n}}$, \\ Bela Bendlova ${ }^{\circ}$, Vlasta Sýkorová ${ }^{\circ}$, Mingzhao Xing ${ }^{\text {a,* }}$
}

\footnotetext{
${ }^{a}$ Laboratory for Cellular and Molecular Thyroid Research, Division of Endocrinology, Diabetes and Metabolism, Department of Medicine. The Johns Hopkins University School of Medicine, Baltimore, MD 21287, USA

${ }^{\mathrm{b}}$ Division of Endocrinology and Metabolism, Department of Internal Medicine, Korea University College of Medicine, Seoul 02841, South Korea

c Section of Endocrinology, Department of Clinical and Experimental Medicine, University of Pisa, Pisa, Italy

d Department of Internal Medicine, University of Perugia, Perugia, Italy

${ }^{\mathrm{e}}$ Division of Endocrine and Metabolic Diseases, IRCCS Instituto Auxologico Italiano, and Department of Pathophysiology and Transplantation, University of Milan, Milan, Italy

${ }^{\mathrm{f}}$ Maria Sklodowska-Curie Institute-Oncology Center, Gliwice Branch, Gliwice, Poland

${ }^{\mathrm{g}}$ Cancer Molecular Pathology of School of Medicine and Menzies Health Institute Queensland, Griffith University, Gold Coast, Australia

${ }^{\mathrm{h}}$ Department of Medicine, Endocrinology Unit, University of Padua, Italy

${ }^{\mathrm{i}}$ Veneto Institute of Oncology, IRCCS, Padua, Italy

${ }^{\mathrm{j}}$ University of Pittsburgh School of Medicine, Pittsburgh, PA, USA

${ }^{\mathrm{k}}$ Department of Endocrinology and Nutrition Hospital Universitario La Paz and Hospital, Universitario De Mostoles, 28029 Madrid, Spain

${ }^{1}$ Biomedical Research Institute "Alberto Sols", Consejo Superior De Investigaciones Cientificas and Univeridad Autonoma de Madrid, 28029, Madrid, Spain

m Ciberonc, Health Institute Carlos III, 28029 Madrid, Spain

${ }^{\mathrm{n}}$ Endocrine Surgical Unit, The University of Sydney, Sydney, Australia

${ }^{\circ}$ Department of Molecular Endocrinology, Institute of Endocrinology, Prague, Czech Republic
}

Received 15 July 2019; received in revised form 5 October 2019; accepted 21 October 2019

Available online 29 November 2019

\footnotetext{
* Corresponding author: Division of Endocrinology, Diabetes and Metabolism, Department of Medicine, Johns Hopkins University School of Medicine, 1830 E Monument Street/Suite 333, Baltimore, MD 21287, USA. Fax: +1 4109558172.

E-mail address: mxing1@jhmi.edu (M. Xing).
} 


\section{KEYWORDS}

Papillary thyroid microcarcinoma; $B R A F$ V600E mutation; Active surveillance; Risk stratification; Prognosis

\section{Introduction}

Papillary thyroid cancer (PTC) is a common endocrine malignancy with a rapidly rising incidence globally in recent decades [1-4]. Papillary thyroid microcarcinoma (PTMC), defined as tumour $\leq 1.0 \mathrm{~cm}$ in its greatest dimension [5], constitutes a major portion of thyroid cancer, close to $50 \%$ of all thyroid malignancies in some studies $[1,6,7]$. The Surveillance, Epidemiology, and End Results (SEER) data have shown an increase in the incidence of PTMC from 3.39 per 100,000 person-years in $1983-1985$ to 13.02 per 100,000 person-years in 2010-2013, with an average annual percent change of 9.3\% [1]. Although the majority of patients with PTMC have an indolent disease course with no serious clinical outcomes, some patients do have tumour metastasis and even disease-specific mortality [8-10]. Of particular note is that recurrence of PTMC can occur after treatment, which may be associated with increased risk of patient morbidity and mortality. Thus, prevention of disease recurrence of PTMC is a major goal of its treatment in the current clinical practice.

It is often difficult to precisely risk stratify and accordingly treat PTMC to achieve an optimal benefitharm balance of the treatments. Therefore, the management style of PTMC, particularly low-risk PTMC, is currently widely variable in different clinical practices around the world, ranging from total thyroidectomy for every patient with PTMC to non-surgical active surveillance in patients with clinically low-risk PTMC. The conservative active surveillance is attractive but controversial as an approach to clinically low-risk PTMC, defined as lack of extrathyroidal extension (ETE), lymph node metastasis (LNM) and distant metastasis (DM), which are well known to be associated with an increased risk of recurrence [9-11]. One major issue is that in some patients initially apparently low-risk PTMC is actually inherently destined, perhaps genetically driven, for a later course of poor prognosis-disease recurrence and even mortality. To identify those patients with PTMC that has clinically apparently low-risk at the initial presentation but has inherently high potential for poor prognosis, such as disease recurrence, is clinically challenging. The opposite is also true-i.e., it may not be always straightforward to identify the cases with apparently low-risk PTMC that is truly of low risk. A novel approach, such as the use of genetic guidance, which could further risk stratify clinically apparently low-risk PTMC, could be useful in helping more precisely to define the management of this common type of thyroid cancer.

In recent years, $B R A F \mathrm{~V} 600 \mathrm{E}$ mutation has been introduced as a genetic prognostic marker to assist the risk evaluation of PTC $[12,13]$. There have also been some studies on PTMC in this regard, but they have been virtually all focused on the overall analyses of 
PTMC with inconsistent results $[11,14,17]$. There are limited data on the prognostic value of $B R A F \mathrm{~V} 600 \mathrm{E}$ in the unique category of PTC-clinically low-risk PTMC. More than ten years ago, Mazzaferri suggested that $B R A F \mathrm{~V} 600 \mathrm{E}$ could be useful in further risk stratification of low-risk PTMC [18], but current clinical guidelines on the treatment of thyroid cancer, such as the American Thyroid Association guidelines, have not been able to specifically define yet $B R A F \mathrm{~V} 600 \mathrm{E}$ as a risk-differentiating factor for low-risk PTMC [19]. This controversy derives largely from the fact that direct data on the prognostic value of $B R A F \mathrm{~V} 600 \mathrm{E}$ in the risk assessment of low-risk PTMC is lacking. There has been particularly lack of a large multicenter study that could provide a strong analysis power to resolve this controversy. In view of this, we conducted the present large international multicenter study to directly investigate the prognostic value of $B R A F \mathrm{~V} 600 \mathrm{E}$ mutation in PTMC, with a particular emphasis on low-risk PTMC.

\section{Materials and methods}

\subsection{Patients and mutational analyses}

This study initially included 2638 patients with PTC from 11 medical centres in six countries, as detailed previously [20-24]. After exclusion of patients with tumour size $>1.0 \mathrm{~cm}$, we had 743 patients with PTMC (584 women and 159 men), with a median age of 49 years (interquartile range [IQR], 39-59 years) and a median clinical follow-up time of 53 months (IQR, 25-93 months) from 1978 to 2015. The clinicopathological demographic characteristics of the patients with PTMC in this cohort from different medical centres are presented in Supplemental Table S1. We defined lowrisk PTMC as having no ETE, LNM, and DM and high-risk PTMC as having at least one of these high-risk characteristics. All patients received total or near-total thyroidectomy. Neck lymph node dissection and radioiodine ablation were pursued when clinically indicated as previously described $[16,22,23]$. Tumour recurrence was defined as combined persistent and recurrent disease confirmed by histologic/cytologic/radiographic/ biochemical criteria as previously described [16]. Follow-up time was defined as the time from initial thyroidectomy to tumour recurrence or to the latest clinical contact in the case of no recurrence. The study was approved by the institutional review board of all the centres involved and informed consent was obtained from patients where required. For $B R A F$ V600E mutation analyses, we amplified exon 15 of the $B R A F$ gene containing the mutation hotspot using polymerase chain reaction primers, as described previously [24-35]. Genetic analyses were performed after surgical and radioiodine ablation treatments in all patients and the $B R A F$ mutation status did not affect the treatment strategy.

\subsection{Statistical analysis}

We presented continuous data as medians and IQRs using the Wilcoxon-Mann-Whitney test for the analysis of non-normally distributed variables and presented categorical data as frequencies and percentage using a chi-squared test for the analysis or Fisher's exact test for small case numbers. Kaplan-Meier survival curves with log-rank test were used to analyse the recurrence-free survival. Independent risk factors associated with disease recurrence were examined by Cox-regression analyses to generate hazard ratio (HR) and $95 \%$ confidence interval $(\mathrm{CI})$. All reported $P$ values were two-sided and a value $<0.05$ was considered significant. All analyses were performed using SPSS version 20.0 (IBM SPSS, Inc. New York, NY) and GraphPad Prism version 7 (GraphPad Software, San Diego, CA).

\section{Results}

\subsection{Effect of BRAF V600E mutation on disease recurrence of PTMC in the overall cohort}

We first took the advantage of this large multicenter cohort of 743 patients with PTMC to examine the general effect of $B R A F \mathrm{~V} 600 \mathrm{E}$ mutation on tumour behaviours, particularly disease recurrence, in the overall PTMC cohort (Table 1). The overall prevalence of $B R A F$ V600E mutation in PTMC was $32.4 \%$ (241/ 743). $B R A F \mathrm{~V} 600 \mathrm{E}$ was associated with several high-risk tumour behaviours, such as ETE and LNM. The tumor recurrence rate in patients with $B R A F$ mutationnegative PTMC was significantly lower compared with that of $B R A F$ mutation-positive patients $(6.4 \%$ versus $10.8 \%$, respectively), with an unadjusted HR of 2.01 (95\% CI, 1.20-3.38), which remained significant at 2.44 (95\% CI, 1.15-5.20) after adjustment for patient age, sex, conventional pathological risk factors, medical centre, and radioactive iodine treatment (Table 2). A significant association between $B R A F$ V600E mutation and decreased recurrence-free survival is also revealed on Kaplan-Meier analysis (log-rank $P=0.007$; Fig. 1A).

Similar results were obtained when the analyses were performed only on a conventional variant of PTMC (CPTMC). The prevalence of $B R A F$ mutation in this group was $32.9 \%(198 / 602)$. Tumour recurrence rates in CPTMC were $6.2 \%(25 / 404)$ versus $12.1 \%(24 / 198)$ in $B R A F$ mutation-negative and BRAF mutation-positive patients, respectively, with an HR of 2.94 (95\% CI, 1.20-7.20) after adjustment for patient age, sex, conventional pathological risk factors, medical centre, and radioactive iodine treatment (Table 2). On Kaplan-Meier analysis, the recurrence-free survival curve of $B R A F$ mutation-positive patients significantly 
Table 1

Clinicopathological demographic characteristics of papillary thyroid microcarcinoma in patients according to the $B R A F$ genotype.

\begin{tabular}{|c|c|c|c|c|}
\hline & All patients & $B R A F$ V600E negative & $B R A F$ V600E positive & $P$-value \\
\hline Total case, $\mathrm{n}(\%)$ & 743 & $502(67.6)$ & $241(32.4)$ & \\
\hline Age, median (interquartile range (IQR)) & $49(39-59)$ & $48(39-59)$ & $49(39-59)$ & 0.706 \\
\hline Female, n $(\%)$ & $584(78.6)$ & $392(78.1)$ & $192(79.7)$ & 0.623 \\
\hline Tumour size, median (IQR), cm & $0.8(0.5-1.0)$ & $0.7(0.5-1.0)$ & $0.8(0.6-1.0)$ & $<0.001$ \\
\hline Extrathyroidal extension, n (\%) & $98(13.2)$ & $44(8.8)$ & $54(22.4)$ & $<0.001$ \\
\hline Lymph node metastasis, $\mathrm{n}(\%)$ & $168(22.6)$ & $95(18.9)$ & $73(30.3)$ & 0.001 \\
\hline Vascular invasion, $\mathrm{n}(\%)$ & $16 / 319(5.0)$ & $11 / 257(4.3)$ & $5 / 62(8.1)$ & 0.209 \\
\hline Multifocality, n (\%) & $281(37.8)$ & $172(34.3)$ & $109(45.2)$ & 0.004 \\
\hline Distant metastasis, n (\%) & $11(1.5)$ & $7(1.4)$ & $4(1.7)$ & 0.754 \\
\hline \multicolumn{5}{|l|}{ Stage (AJCC 8th), n $(\%),(\mathrm{n}=732)$} \\
\hline I & $691(93)$ & $474(95.4)$ & $217(92.3)$ & 0.173 \\
\hline II & $38(5.1)$ & $21(4.2)$ & $17(7.2)$ & \\
\hline III & 0 & 0 & 0 & \\
\hline IV & $3(0.4)$ & $2(0.4)$ & $1(0.4)$ & \\
\hline${ }^{131}$ I treatment, $\mathrm{n}(\%)$ & $447 / 742(60.2)$ & $257 / 501(51.3)$ & $190 / 241(78.8)$ & $<0.001$ \\
\hline${ }^{131}$ I dose, median (IQR), mCi & $50(0-100)$ & $30(0-100)$ & $100(30-101)$ & $<0.001$ \\
\hline Follow time, median (IQR), months & $53(25-93)$ & $56(29.5-99)$ & $40(21-83)$ & $<0.001$ \\
\hline Tumour recurrence, n $(\%)$ & $58(7.8)$ & $32(6.4)$ & $26(10.8)$ & 0.041 \\
\hline
\end{tabular}

Table 2

Hazard ratios of $B R A F \mathrm{~V} 600 \mathrm{E}$ mutation for recurrence of PTMC on the overall analysis.

\begin{tabular}{|c|c|c|c|c|c|}
\hline & \multirow[t]{2}{*}{ Recurrence n (\%) } & \multicolumn{2}{|l|}{ Unadjusted } & \multicolumn{2}{|l|}{ Adjusted $^{\mathrm{a}}$} \\
\hline & & HR $(95 \% \mathrm{CI})$ & $P$-value & $\operatorname{HR}(95 \% \mathrm{CI})$ & $P$-value \\
\hline \multicolumn{6}{|l|}{ All PTMCs } \\
\hline$B R A F$ V600E negative & $32 / 502(6.4)$ & 1 (reference) & & 1 (reference) & \\
\hline$B R A F \mathrm{~V} 600 \mathrm{E}$ positive & $26 / 241(10.8)$ & $2.01(1.20-3.38)$ & 0.008 & $2.44(1.15-5.20)$ & 0.020 \\
\hline \multicolumn{6}{|l|}{ Conventional PTMC } \\
\hline$B R A F \mathrm{~V} 600 \mathrm{E}$ negative & $25 / 404(6.2)$ & 1 (reference) & & 1 (reference) & \\
\hline$B R A F \mathrm{~V} 600 \mathrm{E}$ positive & 24/198 (12.1) & $2.29(1.30-4.01)$ & 0.004 & $2.94(1.20-7.20)$ & 0.018 \\
\hline
\end{tabular}

PTMC, papillary thyroid microcarcinoma; CI, confidential interval.

${ }^{a}$ Adjusted for patient age at diagnosis, sex, tumour size, cervical lymph node metastasis, extrathyroidal extension, vascular invasion, multifocality, medical centres, and radioactive iodine treatments.

decreased compared with that of $B R A F$ mutationnegative patients $(\log$-rank $P=0.003$; Fig. $1 \mathrm{~B})$.

\subsection{Effect of BRAF V600E mutation on disease recurrence of low- and high-risk PTMCs}

We next examined the effect of $B R A F$ V600E mutation on disease recurrence of PTMC in different risk groups. As shown in Table 3, the overall BRAF V600E rate was $26.6 \%(139 / 522)$ and disease recurrence rate was $2.1 \%$ $(11 / 522)$ in low-risk PTMC. The recurrence rates were $1.3 \%$ versus $4.3 \%$ in $B R A F$ mutation-negative versus $B R A F$ mutation-positive patients, respectively, with a HR of 6.65 (95\% CI, 1.80-24.65) after adjustment for patient age, sex, medical centre, and radioactive iodine treatment. The negative predictive value of $B R A F \mathrm{mu}-$ tation for recurrence of low-risk PTMC was $98.7 \%$ (95\% CI, 96.8\%-99.5\%) (Table 3). In the high-risk group, however, $B R A F$ mutation had no significant effect on tumour recurrence, with a HR of $1.28(95 \%$ CI, $0.69-2.37$ ) after adjustment for patient age, sex, medical centre, and radioactive iodine treatment. On Kaplan-Meier analysis, $B R A F$ mutation was associated with a significant decrease in recurrence-free survival curve in low-risk PTMC (log-rank $P=0.023$; Fig. 2A), whereas in the high-risk group, $B R A F$ mutation had no significant effect on the recurrence-free survival curve (log-rank $P=0.688$; Fig. 2B).

Similar results were obtained in CPTMC. The recurrence rate in low-risk CPTMC was $1.3 \%$ versus $4.3 \%$ in $B R A F$ mutation-negative versus $B R A F$ mutation-positive patients, with a HR of 5.15 (95\% CI, 1.21 to 21.83) after adjustment for patients age, sex, medical centre, and radioactive iodine treatment (Table 3). In high-risk CPTMC, BRAF mutation had no effect on tumour recurrence, with an adjusted HR of $1.34(95 \%$ CI, 0.71 to 2.56). On Kaplan-Meier analyses, $B R A F$ mutation was associated with a significant decline in the recurrence-free survival curve in low-risk CPTMC (logrank $P=0.036$; Fig. 2C), but not in high-risk CPTMC (log-rank $P=0.422$; Fig. 2D).

\section{Discussion}

It can be a challenging task to precisely risk stratify patients with PTMC for prognostic risk level-based 
A

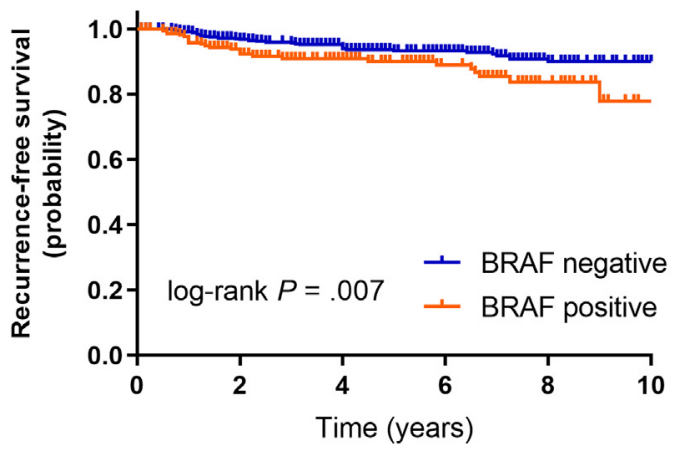

B

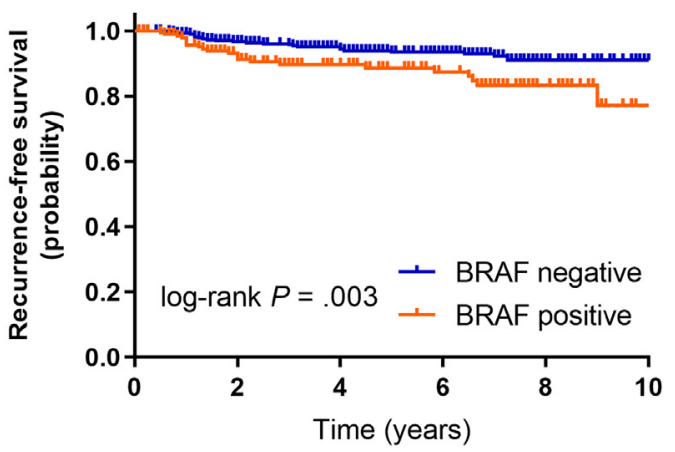

Fig. 1. Kaplan-Meier analysis of disease recurrence-free survival by BRAF V600E mutation status in papillary thyroid microcarcinoma (PTMC). A. All types of PTMC. B. Conventional variant of PTMC. Comparison of recurrence-free survival was performed between $B R A F$ V600E mutation-positive and wild-type $B R A F$ patients using the log-rank test. Follow-up time is truncated at 10 years.

appropriate managements, particularly apparently lowrisk cases. Although patients with PTMC generally have an excellent prognosis [36,37], some patients experience tumour recurrence and even mortality $[9,10]$, suggesting that all PTMCs do not have the same intrinsic risk for poor outcomes. There are currently ongoing debates particularly on how to further risk stratify and appropriately manage clinically apparently low-risk PTMC. Controversies exist particularly on how to select cases of such low-risk PTMC for conservative active surveillance.

In this context, the present large international multicenter study has demonstrated that $B R A F \mathrm{~V} 600 \mathrm{E}$ mutation can be a prognostic marker for poorer clinicopathological outcomes of PTMC, particularly for disease recurrence of low-risk PTMC. In fact, this study has for the first time shown that $B R A F$ mutation can further differentiate the recurrence risk of clinically lowrisk PTMC-wild-type $B R A F$ patients have an extremely low risk of recurrence whereas $B R A F$ mutation patients have a significantly increased recurrence risk, representing an independent prognostic value of $B R A F$ mutation in the apparently clinically low-risk PTMC. Unlike in low-risk PTMC, in high-risk PTMC, $B R A F \mathrm{~V} 600 \mathrm{E}$ mutation was not an independent risk factor for disease recurrence in the present study. This finding may be expected, given the fact that even in the absence of $B R A F$ mutation, classical high-risk tumour features already existed in high-risk PTMC as defined in the present study, which would be associated with a high recurrence rate. These findings in the present study by analysing low- and high-risk PTMCs separately may now reconcile the inconsistent results of previous studies on the prognostic value of $B R A F \mathrm{~V} 600 \mathrm{E}$ in the overall analyses of all PTMCs as the outcomes of those studies would vary depending on the compositae portions of low- and high-risk PTMCs in the cohorts of patients included [11,14-17].

Active surveillance has been recently proposed as an alternative option to surgical treatment in low-risk PTMC, which is drawing increasing attention
$[19,38,39]$. It is of concern, however, that all low-risk PTMCs may not uniformly remain "silent" without clinical consequences [40-42]. It is also unknown what molecular markers can distinguish intrinsically aggressive but initially apparently low-risk PTMC from truly indolent low-risk PTMC. A striking finding in the present study was the extremely low recurrence rate in lowrisk PTMC that harboured the wild-type $B R A F$, representing a robust negative predictive value $(99 \%)$ of $B R A F \mathrm{~V} 600 \mathrm{E}$ for disease recurrence. It has been recently recommended by Miyauchi and Ito that active surveillance is the primary approach to the management of clinically low-risk PTMC as opposed to immediate surgical treatment [43]. Our present study suggests that this conservative approach is reasonable for $B R A F$ mutation-negative low-risk PTMC given its extremely low recurrence rate. This is supported also by the fact that virtually no PTC-related mortality occurred in patients with $B R A F$ mutation-negative PTC, particularly in patients with conventional PTC, including even PTC $>1.0 \mathrm{~cm}$ [44]. In this context, because the cost of $B R A F$ test is generally low and the cost of thyroidectomy is high, this $B R A F$ status-based approach to the management of PTMC would spare many patients from total thyroidectomy or even any thyroidectomy and would thus likely be cost-saving, in addition to other advantages.

Our present study demonstrated that $B R A F$ V600E mutation could independently define a significantly increased risk of disease recurrence in initially apparently low-risk PTMC. This finding, together with the well-known other adverse effects of $B R A F \mathrm{~V} 600 \mathrm{E}$ on PTC $[12,13,16,24]$, suggests that non-surgical long-term surveillance may not be appropriate for patients with $B R A F$ mutation-positive low-risk PTMC. Even a recurrence rate of $4.3 \%$ in the $B R A F$ mutation-positive low-risk PTMC found in the present study seems to be relatively low; this significant increase in recurrence risk compared with BRAF mutation-negative PTMC suggests a significantly increased aggressive potential of the tumour associated with $B R A F \mathrm{~V} 600 \mathrm{E}$. This is a concern 
Table 3

Hazard ratios of $B R A F$ V600E mutation for recurrence of PTMC in low- and high-risk groups.

\begin{tabular}{|c|c|c|c|c|c|c|c|c|c|}
\hline & \multicolumn{4}{|c|}{ tumour recurrence } & \multicolumn{2}{|l|}{ Unadjusted } & \multicolumn{2}{|l|}{ Adjusted $^{\mathrm{a}}$} & \multirow{2}{*}{$\begin{array}{l}\text { Negative predictive value, } \% \\
(95 \% \mathrm{CI})\end{array}$} \\
\hline & $\begin{array}{l}\text { Overall, } \mathrm{n} \\
(\%)\end{array}$ & $\begin{array}{l}B R A F \mathrm{~V} 600 \mathrm{E} \\
\text { negative, } \mathrm{n}(\%)\end{array}$ & $\begin{array}{l}B R A F \mathrm{~V} 600 \mathrm{E} \\
\text { positive, } \mathrm{n}(\%)\end{array}$ & $\begin{array}{l}P \text { - } \\
\text { value }\end{array}$ & $\begin{array}{l}\mathrm{HR}(95 \% \\
\mathrm{CI})\end{array}$ & $\begin{array}{l}P \text { - } \\
\text { value }\end{array}$ & $\begin{array}{l}\mathrm{HR}(95 \% \\
\mathrm{CI})\end{array}$ & $\begin{array}{l}P \text { - } \\
\text { value }\end{array}$ & \\
\hline \multicolumn{10}{|l|}{ All PTMCs } \\
\hline $\begin{array}{l}\text { Low-risk } \\
\text { group }\end{array}$ & $\begin{array}{l}11 / 522 \\
(2.1)\end{array}$ & $5 / 383(1.3)$ & $6 / 139(4.3)$ & 0.076 & $\begin{array}{l}3.63(1.11 \\
-11.91)\end{array}$ & 0.033 & $\begin{array}{l}6.65(1.80 \\
-24.65)\end{array}$ & 0.005 & 98.7 (96.8-99.5) \\
\hline $\begin{array}{l}\text { High-risk } \\
\text { group }\end{array}$ & $\begin{array}{l}47 / 221 \\
(21.3)\end{array}$ & $27 / 119(22.7)$ & 20/102 (19.6) & 0.577 & $\begin{array}{l}1.13(0.63 \\
-2.02)\end{array}$ & 0.689 & $\begin{array}{l}1.28(0.69 \\
-2.37)\end{array}$ & 0.437 & $77.3(68.5-84.3)$ \\
\hline \multicolumn{10}{|c|}{ Conventional PTMC } \\
\hline $\begin{array}{l}\text { Low-risk } \\
\text { group }\end{array}$ & $9 / 423(2.1)$ & 4/308 (1.3) & $5 / 115(4.3)$ & 0.066 & $\begin{array}{l}3.71(1.00 \\
-13.85)\end{array}$ & 0.051 & $\begin{array}{l}5.15(1.21 \\
-21.83)\end{array}$ & 0.026 & 98.7 (96.5-99.6) \\
\hline $\begin{array}{l}\text { High-risk } \\
\text { group }\end{array}$ & $\begin{array}{l}40 / 179 \\
(22.3)\end{array}$ & 21/96 (21.9) & $19 / 83(22.9)$ & 0.871 & $\begin{array}{l}1.29(0.69 \\
-2.41)\end{array}$ & 0.424 & $\begin{array}{l}1.34(0.71 \\
-2.56)\end{array}$ & 0.369 & $78.1(68.3-85.7)$ \\
\hline
\end{tabular}

PTMC, papillary thyroid microcarcinoma; CI, confidential interval.

${ }^{a}$ Adjusted for patient age at diagnosis, sex, medical centres, and radioactive iodine treatments.

A

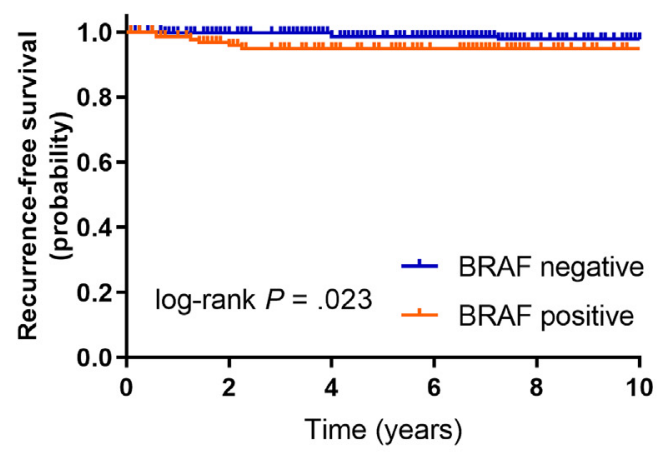

C

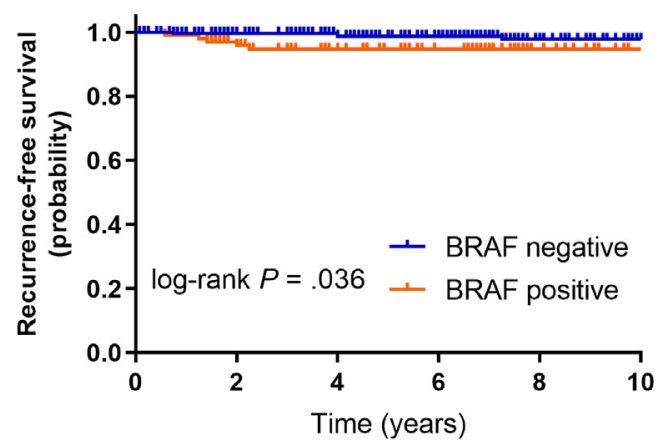

B

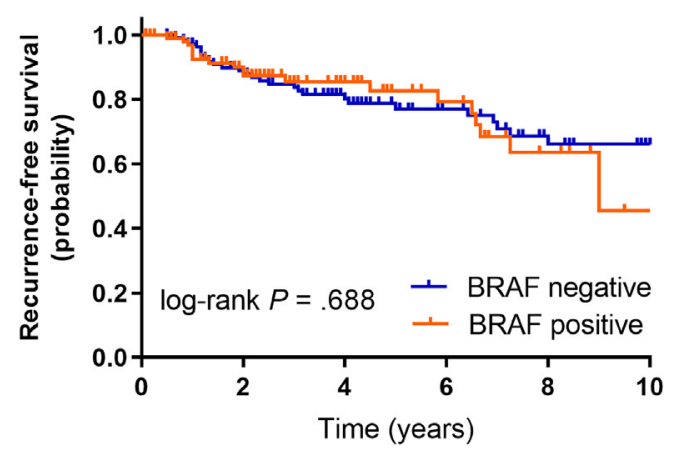

D

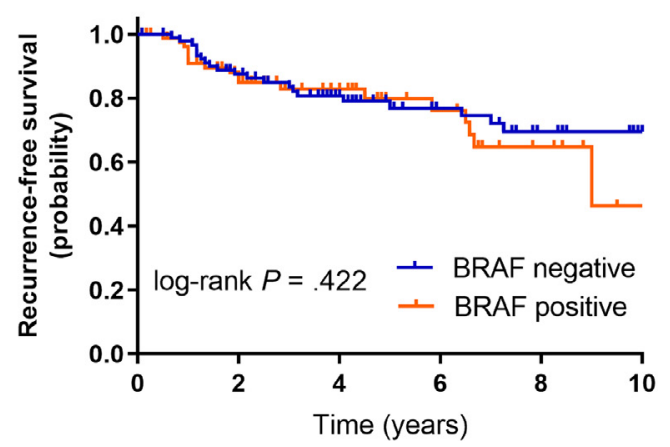

Fig. 2. Kaplan-Meier analysis of disease recurrence-free survival by BRAF V600E mutation status in PTMC of different risks. A. Lowrisk PTMC; B. high-risk PTMC; C. low-risk conventional PTMC; and D. high-risk conventional PTMC. Comparison of recurrence-free survival was performed between $B R A F$ V600E mutation-positive and wild-type $B R A F$ patients using the log-rank test. Follow-up time was truncated at 10 years.

particularly given that the long-term impact of $B R A F$ mutation on clinical outcomes of thyroid cancer will likely be substantial if significant tumour growth, ETE, or LNM occurs. This is because previous findings suggest that $B R A F$ V600E-positive intrathyroidal PTC $>1.0 \mathrm{~cm}$ has a substantially increased recurrence risk, particularly in the case of tumours $>2.0 \mathrm{~cm}$ where there was a robustly increased recurrence risk to around 20-30\%, which was comparable with the recurrence risk of invasive PTC [21]. It has been previously demonstrated that $B R A F$ V600E and ETE or LNM has a robustly synergistic adverse effect on clinical outcomes of PTC, including disease recurrence [16] and patient mortality [24]. New ETE and LNM can develop even in initially low-risk PTMC if given sufficient time and even in the absence of significant growth of the primary tumour. Once ETE and LNM occur in BRAF V600Epositive tumour, synergistic interactive effects between the newly developed aggressive pathological factors and $B R A F \mathrm{~V} 600 \mathrm{E}$ on poor clinical outcomes of PTMC may 
intensify [16,24]. Moreover, the adverse effects of $B R A F$ V600E on clinical outcomes of PTC, such as diseasespecific mortality, start to be significantly manifested particularly after 10 years of clinical follow-up from the initial treatment [24]. Therefore, BRAF mutationpositive low-risk PTMC has an aggressive potential if left untreated, making uncertain the feasibility of the long-term non-surgical conservative surveillance for such $B R A F$ mutation-positive thyroid cancer. It is worth noting that $B R A F$ mutation was found only in $26.6 \%$ of patients with clinically low-risk PTMC in the present study. Thus, if the $B R A F$ mutation status is used to assist the management of low-risk PTMC, the vast majority of patients could be managed with conservative surveillance although only a minority of patients need to pursue thyroidectomy. It has been recently recommended that a clinical risk level-based approach in the prognostic use of $B R A F$ mutation to the management of PTC be applied and, as such, thyroid lobectomy may be just adequate for $B R A F$ mutation-positive low-risk PTMC [45].

A limitation of the present study was the relatively small number of patients in the high-risk group of PTMC, reducing the power to conclude the results. Previous studies demonstrated that even though $B R A F$ mutation-negative PTC could have recurrence [16,46], PTC-related mortality virtually only occurred in patients with $B R A F$ mutation-positive PTC [44]. Thus, the $B R A F$ mutation status may also have a prognostic value even in high-risk PTMC: absence of the mutation implies virtually no PTMC-related mortality. The lack of information on other mutations, such as rat sarcoma $(R A S)$ mutations and telomerase reverse transcriptase (TERT) promoter mutation, is another limitation of this study. However, RAS mutations are mutually exclusive with $B R A F$ V600E [47] and they alone do not have adverse effects on the outcomes of low-risk PTC [45]. TERT promoter mutation is uncommon in PTMC, which alone is also not associated with aggressiveness of PTMC [48]. We analysed the Johns Hopkins cases, which had information on both the BRAF and TERT mutations, and found that TERT promoter mutation alone indeed had no effect, whereas $B R A F$ mutation alone had a significant effect on disease recurrence either in the overall analysis of all PTMCs or low-risk PTMC; in fact, a remarkable recurrence rate of $13.5 \%(5 / 37)$ was observed in the group with $B R A F$ mutation alone versus only $1.6 \%(3 / 189)$ in the group with no mutation (Supplemental Table S2). BRAF V600E and TERT promoter mutations often coexist in PTC to form an oncogenic genetic duet that is associated with a robustly increased risk of poor clinical outcomes of PTC $[44,46]$. The number of cases with this genetic duet was too small in PTMC, particularly low-risk PTMC, to analyse in the present study (Supplemental Table S2).

In summary, in this large multicenter study, we demonstrate that $B R A F \mathrm{~V} 600 \mathrm{E}$ can further differentiate the prognostic risk of low-risk PTMC: the mutation has an extremely robust negative predictive value for disease recurrence and is associated with a significantly increased recurrence. These results, together with the known aggressive role of $B R A F \mathrm{~V} 600 \mathrm{E}$ in PTC in general, suggest that $B R A F$ mutation-positive PTMC can be reasonably treated surgically; the feasibility of longterm conservative surveillance of $B R A F$ mutationpositive PTMC initially presenting with low-risk clinical features seems uncertain, making it reasonable at this time to treat such thyroid cancer surgically, albeit with limited surgical extent-thyroid lobectomy, for example. In contrast, conservative management in the form of non-surgical active surveillance is reasonable for $B R A F$ mutation-negative low-risk PTMC, which accounts for the majority of patients with clinically lowrisk PTMC. Thus, more precise management of patients with low-risk PTMC can be achieved by including the $B R A F \mathrm{~V} 600 \mathrm{E}$ mutation status in the prognostic risk stratification.

\section{Conflict of interest statement}

Mingzhao Xing receives royalties as co-holder of a licensed USA patent related to $B R A F \mathrm{~V} 600 \mathrm{E}$ mutation in thyroid cancer. Other authors have no conflict of interest to disclose.

\section{Funding/support}

This study was supported partly by US National Institutes of Health (NIH) Grant Nos. R01CA215142 and R01CA189224 (M.X.) and by the following additional funding at the individual participating centres:

Polish National Center of Research and Development MILESTONE (Molecular Diagnostics and Imaging in Individualized Therapy for Breast, Thyroid and Prostate Cancer) Project Grant No. STRATEGMED2/ 267398/4/NCBR/2015 (A.C., B.J.); grants from the Menzies Health Institute, Griffith University, Queensland Cancer Council, and Queensland Smart State Fellowship in Australia (A.K.L.); Ministry of Economy and Competitiveness (MINECO) and Fondo Europeo de Desarrollo Regional (FEDER) Grant No. SAF201675531-R, Instituto de Salud Carlos III Grant No. PI14/ 01980, Asociación Española Contra el Cáncer Foundation Grant No. GCB14142311CRES, and TIRONET2-CM Grant No. B2017/BMD-3724 TIRONET2-CM in Spain (P.S., G.R.-E.); Institute of Endocrinology Grant Nos. AZV 16-32665A and MH CZ-DRO 00023761 in the Czech Republic (B.B., V.S.); grants from the New South Wales Cancer Institute (C.J.O.) and Cancer Council of New South Wales (R.C.B.) in Australia; National Institute on Aging, NIH, Grant No. 5R03AG042334-02 (L.Y.); grants from the Ministero della Istruzione Universitaria e Ricerca 
Scientifica, the Associazione Italiana per la Ricerca sul Cancro, the Istituto Toscano Tumori, and the Ministero della Salute in Italy (D.V. and R.E.).

\section{Role of the funding Sources}

The funding organizations had no role in the design and conduct of the study; the collection, management, analysis, and interpretation of the data; or the preparation, review, or approval of the manuscript.

\section{Disclaimer}

The content of this article is solely the responsibility of the authors and does not necessarily reflect the official views of the NIH or the funding entities of the individual centres participated in this study.

\section{Appendix A. Supplementary data}

Supplementary data to this article can be found online at https://doi.org/10.1016/j.ejca.2019.10.017.

\section{References}

[1] Lim H, Devesa SS, Sosa JA, Check D, Kitahara CM. Trends in thyroid cancer incidence and mortality in the United States, 19742013. J Am Med Assoc 2017;317:1338-48.

[2] Siegel RL, Miller KD, Jemal A. Cancer Statistics, 2017. CA Cancer J Clin 2017;67:7-30.

[3] Noone AM, Howlader N, Krapcho M, Miller D, Brest A, Yu M, et al. SEER cancer statistics review, 1975-2015. Bethesda, MD, National Cancer Institute. https://seer.cancer.gov/csr/1975_2015. Accessed November, 2017.

[4] Ferlay J, Soerjomataram I, Ervik M, Dikshit R, Eser S, Mathers C, et al. Cancer incidence and mortality worldwide: IARC cancer base no. 11. Lyon, France: International Agency for Research on Cancer; 2013.

[5] Lloyd RV, Osamura RY, Klöppel G, Rosai J. WHO classification of tumours of endocrine organs. 4th ed. Lyon, France: International Agency for Research on Cancer; 2017.

[6] Davies L, Welch HG. Increasing incidence of thyroid cancer in the United States, 1973-2002. J Am Med Assoc 2006;295:2164-7.

[7] Cho BY, Choi HS, Park YJ, Lim JA, Ahn HY, Lee EK, et al. Changes in the clinicopathological characteristics and outcomes of thyroid cancer in Korea over the past four decades. Thyroid 2013;23:797-804.

[8] Roti E, degli Uberti EC, Bondanelli M, Braverman LE. Thyroid papillary microcarcinoma: a descriptive and meta-analysis study. Eur J Endocrinol 2008;159:659-73.

[9] Chow SM, Law SC, Chan JK, Au SK, Yau S, Lau WH. Papillary microcarcinoma of the thyroid-prognostic significance of lymph node metastasis and multifocality. Cancer 2003;98:31-40.

[10] Pedrazzini L, Baroli A, Marzoli L, Guglielmi R, Papini E. Cancer recurrence in papillary thyroid microcarcinoma: a multivariate analysis on 231 patients with a 12-year follow-up. Minerva Endocrinol 2013;38:269-79.

[11] Zheng X, Wei S, Han Y, Li Y, Yu Y, Yun X, et al. Papillary microcarcinoma of the thyroid: clinical characteristics and BRAF(V600E) mutational status of 977 cases. Ann Surg Oncol 2013;20:2266-73.
[12] Xing M, Haugen BR, Schlumberger M. Progress in molecularbased management of differentiated thyroid cancer. Lancet 2013;381:1058-69.

[13] Xing M. Molecular pathogenesis and mechanisms of thyroid cancer. Nat Rev Cancer 2013;13:184-99.

[14] Walczyk A, Kowalska A, Kowalik A, Sygut J, Wypiórkiewicz E, Chodurska R, et al. The BRAFV600E mutation in papillary thyroid microcarcinoma: does the mutation have an impact on clinical outcome? Clin Endocrinol 2014;80:899-904.

[15] Kim TY, Kim WB, Rhee YS, Song JY, Kim JM, Gong G, et al. The BRAF mutation is useful for prediction of clinical recurrence in low-risk patients with conventional papillary thyroid carcinoma. Clin Endocrinol 2006;65:364-8.

[16] Xing M, Alzahrani AS, Carson KA, Shong YK, Kim TY, Viola D, et al. Association between BRAF V600E mutation and recurrence of papillary thyroid cancer. J Clin Oncol 2015;33: $42-50$.

[17] Chen Y, Sadow PM, Suh H, Lee KE, Choi JY, Suh YJ, et al. $\mathrm{BRAF}(\mathrm{V} 600 \mathrm{E})$ is correlated with recurrence of papillary thyroid microcarcinoma: a systematic review, multi-institutional primary data analysis, and meta-analysis. Thyroid 2016;26:248-55.

[18] Mazzaferri EL. Managing small thyroid cancers. J Am Med Assoc 2006;295:2179-82.

[19] Haugen BR, Alexander EK, Bible KC, Doherty GM, Mandel SJ, Nikiforov YE, et al. 2015 American thyroid association management guidelines for adult patients with thyroid nodules and differentiated thyroid cancer: the American thyroid association guidelines task force on thyroid nodules and differentiated thyroid cancer. Thyroid 2016;26:1-133.

[20] Wang F, Yu X, Shen X, Zhu G, Huang Y, Liu R, et al. The prognostic value of tumor multifocality in clinical outcomes of papillary thyroid cancer. J Clin Endocrinol Metab 2017;102: 3241-50.

[21] Huang Y, Qu S, Zhu G, Wang F, Liu R, Shen X, et al. BRAF V600E mutation-assisted risk stratification of solitary intrathyroidal papillary thyroid cancer for precision treatment. J Natl Cancer Inst 2018;110:362-70.

[22] Shen X, Zhu G, Liu R, Viola D, Elisei R, Puxeddu E, et al. Patient age-associated mortality risk is differentiated by BRAF V600E status in papillary thyroid cancer. J Clin Oncol 2018;36: 438-45.

[23] Wang F, Zhao S, Shen X, Zhu G, Liu R, Viola D, et al. BRAF V600E confers male sex disease-specific mortality risk in patients with papillary thyroid cancer. J Clin Oncol 2018;36:2787-95.

[24] Xing M, Alzahrani AS, Carson KA, Viola D, Elisei R, Bendlova B, et al. Association between BRAF V600E mutation and mortality in patients with papillary thyroid cancer. J Am Med Assoc 2013;309:1493-501.

[25] Puxeddu E, Moretti S, Elisei R, Romei C, Pascucci R, Martinelli M, et al. BRAF(V599E) mutation is the leading genetic event in adult sporadic papillary thyroid carcinomas. J Clin Endocrinol Metab 2004:89:2414-20.

[26] Fugazzola L, Mannavola D, Cirello V, Vannucchi G, Muzza M, Vicentini L, et al. BRAF mutation in an Italian cohort of thyroid cancers. Clin Endocrinol 2004;61:239-43.

[27] Xing M, Westra WH, Tufano RP, Cohen Y, Rosenbaum E, Rhoden KJ, et al. BRAF mutation predicts a poorer clinical prognosis for papillary thyroid cancer. J Clin Endocrinol Metab 2005;90:6373-9.

[28] Riesco-Eizaguirre G, Gutierrez-Martinez P, Garcia-Cabezas MA, Nistal M, Santisteban P. The oncogene BRAF V600E is associated with a high risk of recurrence and less differentiated papillary thyroid carcinoma due to the impairment of NA+/I- targeting to the membrane. Endocr Relat Cancer 2006;13:257-69.

[29] Elisei R, Ugolini C, Viola D, Lupi C, Biagini A, Giannini R, et al. BRAF(V600E) mutation and outcome of patients with papillary thyroid carcinoma: a 15-year median follow-up study. J Clin Endocrinol Metab 2008;93:3943-9. 
[30] Xing M, Clark D, Guan H, Ji M, Dackiw A, Carson KA, et al. BRAF mutation testing of thyroid fine-needle aspiration biopsy specimens for preoperative risk stratification in papillary thyroid cancer. J Clin Oncol 2009:27:2977-82.

[31] Yip L, Nikiforova MN, Carty SE, Yim JH, Stang MT, Tublin MJ, et al. Optimizing surgical treatment of papillary thyroid carcinoma associated with BRAF mutation. Surgery 2009; 146:1215-23.

[32] Sykorova V, Dvorakova S, Ryska A, Vcelak J, Vaclavikova E, Laco J, et al. BRAFV600E mutation in the pathogenesis of a large series of papillary thyroid carcinoma in Czech Republic. J Edocrinol Investig 2010;33:318-24.

[33] Czarniecka A, Rusinek D, Stobiecka E, Krajewska J, Kowal M, Kropińska A, et al. Occurrence of BRAF mutations in a Polish cohort of PTC patients - preliminery results. Endokrynol Pol 2010;61:462-6.

[34] O'Neill CJ, Bullock M, Chou A, Sidhu SB, Delbridge LW, Robinson BG, et al. BRAF(V600E) mutation is associated with an increased risk of nodal recurrence requiring reoperative srugery in patients with papillary thyroid cancer. Surgery $2010 ; 148$ $1139-45$

[35] Smith RA, Salajegheh A, Weinstein S, Nassiri M, Lam AK. Correlation between BRAF mutation and the clinicopathological parameters in papillary thyroid carcinoma with particular reference to follicular variant. Hum Pathol 2011;42:500-6.

[36] Hay I. Management of patients with low-risk papillary thyroid carcinoma. Endocr Pract 2007;13:521-33.

[37] Yu XM, Wan Y, Sippel RS, Chen H. Should all papillary thyroid microcarcinomas be aggressively treated? An analysis of 18,445 cases. Ann Surg 2011;254:653-60.

[38] Ito Y, Miyauchi A, Kihara M, Higashiyama T, Kobayashi K, Miya A. Patient age is significantly related to the progression of papillary microcarcinoma of the thyroid under observation. Thyroid 2014;24:27-34.
[39] Ito Y, Miyauchi A, Inoue H, Fukushima M, Kihara M, Higashiyama T, et al. An observational trial for papillary thyroid microcarcinoma in Japanese patients. World J Surg 2010;34: $28-35$.

[40] Oh H-S, Ha J, Kim HI, Kim TH, Kim WG, Lim DJ, et al. Active surveillance of low-risk papillary thyroid microcarcinoma: a multi-center cohort study in Korea. Thyroid 2018;28:1587-94.

[41] Brito JP, Ito Y, Miyauchi A, Tuttle RM. A clinical framework to facilitate risk stratification when considering an active surveillance alternative to immediate biopsy and surgery in papillary microcarcinoma. Thyroid 2016;26:144-9.

[42] Lo CY, Chan WF, Lang BH, Lam KY, Wan KY. Papillary microcarcinoma: is there any difference between clinically overt and occult tumors? World J Surg 2006;30:759-66.

[43] Miyauchi A, Ito Y. Conservative surveillance management of low-risk papillary thyroid microcarcinoma. Endocrinol Metab Clin N Am 2019;48(1):215-26.

[44] Liu R, Bishop J, Zhu G, Zhang T, Landenson PW, Xing M. Mortality risk stratification by combining BRAF V600E and TERT promoter mutations in papillary thyroid cancer: genetic duet of BRAF and TERT promoter mutations in thyroid cancer mortality. JAMA Oncol 2017;3:202-8.

[45] Xing M. Genetic-guided risk assessment and management of thyroid cancer. Endocrinol Metab Clin N Am 2019;48:109-24.

[46] Xing M, Liu R, Liu X, Murugan AK, Zhu G, Zeiger MA, et al. BRAF V600E and TERT promoter mutations cooperatively identify the most aggressive papillary thyroid cancer with highest recurrence. J Clin Oncol 2014;32:2718-26.

[47] Xing M. BRAF mutation in thyroid cancer. Endocr Relat Cancer 2005; $12: 245-62$.

[48] de Biase D, Gandolfi G, Ragazzi M, Eszlinger M, Sancisi V, Gugnoni M, et al. TERT promoter mutations in papillary thyroid microcarcinomas. Thyroid 2015;25:1013-9. 